\title{
EDUCAÇÃO ESPECIAL E INCLUSIVA EM TEMPOS DE PANDEMIA
}

\author{
https://dx.doi.org/10.48097/2674-8673.2022n6p06
}

\author{
Liliane Bastos Lins ${ }^{1}$ \\ Shirley Fernanda Gomes ${ }^{2}$ \\ Kelly Santos ${ }^{3}$
}

\begin{abstract}
RESUMO
Este trabalho apresenta uma pesquisa acadêmica que visa analisar as aulas na Educação Especial e Inclusiva durante o período de Pandemia do COVID - 19 no município de Jaboatão dos Guararapes, em Pernambuco. Quanto à metodologia, a pesquisa trata de um levantamento de dados no intuito de obter os resultados necessários para $\mathrm{o}$ desenvolvimento deste trabalho, sendo também uma pesquisa de cunho qualitativa, por buscar compreender como ocorreram as aulas da Educação Especial e Inclusiva em Jaboatão dos Guararapes. Trata-se, ainda, de uma pesquisa descritiva e exploratória quanto aos seus objetivos. Por meio desse levantamento, e também das respostas recebidas por meio de questionário virtual, foi compreendido que mesmo existindo leis que visam à inserção das crianças com deficiência nas escolas, e que essas crianças tenham uma garantia de igualdade no processo de ensino-aprendizagem, constatou-se que durante o período pandêmico, vivenciado no ano de 2020, a maior parte destes alunos não foi inclusa neste processo, visto que as aulas propostas para tal período não foi acessível, de fato, para esse alunado. Com isso, podemos afirmar que embora existam leis que obrigam o Estado a garantir uma educação igualitária para todos, na prática, ainda há uma lacuna a ser preenchida para que de fato isso ocorra.
\end{abstract}

Palavras-chave: Educação Inclusiva. Educação Especial. Pandemia.

Data de submissão: 09/09/2021

Data de aprovação: 14/10/2021

\begin{abstract}
This work presents an academic research that aims to analyze the classes in Special and Inclusive Education during the period of the COVID Pandemic - 19 in the municipality of Jaboatão dos Guararapes, in Pernambuco. As for the methodology, the research deals with a data collection in order to obtain the necessary results for the development of this work, being also a qualitative research, as it seeks to understand how the Special and Inclusive Education classes occurred in Jaboatão dos Guararapes. It is also a descriptive and exploratory research regarding its objectives. Through this survey, and also from the responses received through a virtual questionnaire, it was understood that even though

\footnotetext{
${ }^{1}$ Graduanda do Curso de Licenciatura em Pedagogia da Faculdade Metropolitana da Grande Recife.

E-mail: lilijuliabastos@gmail.com

2 Graduanda do Curso de Licenciatura em Pedagogia da Faculdade Metropolitana da Grande Recife.

E-mail: shirleyfpg81@gmail.com

${ }^{3}$ Docente Orientadora do Curso de Licenciatura em Pedagogia da Faculdade Metropolitana da Grande Recife.

E-mail:kelmelct@live.com
} 
there are laws aimed at the inclusion of children with disabilities in schools, and that these children have a guarantee of equality in the teaching-learning process, he found It should be noted that during the pandemic period, experienced in 2020, most of these students were not included in this process, since the classes proposed for such period were not, in fact, accessible to these students. With that, we can say that although there are laws that oblige the State to guarantee an egalitarian education for all, in practice, there is still a gap to be filled so that this actually happens.

Keywords: Inclusive Education. Special education. Pandemic.

\section{INTRODUÇÃO}

A Educação Especial surge no Brasil em meados do século XIX, porém de modo muito sutil, ela vem na expectativa de oferecer uma escolaridade diferenciada para pessoas com deficiência. No início do século XX surgem então as primeiras Escolas Especiais no Brasil, tendo como pioneira a "Escola dos Meninos Surdos" como era conhecida inicialmente, no ano de 1857, fundada pelo professor Ernest Huet, que se tornou surdo devido a uma infecção causada pelo sarampo. Ele desenvolveu o primeiro alfabeto Libras no Brasil, unindo seu conhecimento da Língua de Sinais Francesa ao alfabeto brasileiro.

Ao longo dos anos, através deste avanço, veio então a necessidade de inclusão das pessoas com deficiência nas escolas, mas desta vez, escolas regulares. Porém, só no ano de 1994, fala-se realmente da Educação Inclusiva, fazendo um elo com a Educação Especial, levando ao conhecimento de que educação é um direito de todos.

De acordo com o Estatuto da Criança e do Adolescente (ECA), Lei. 8.069 de 1990, o direito a um atendimento especializado às crianças com deficiência, preferencialmente na rede regular de ensino, devem ser garantidos, assim como A Lei de Diretrizes e Bases da Educação Nacional - LDB 9.394/96, no capítulo V, retrata a obrigatoriedade da inclusão dessas crianças na sala de aula regular. Contudo, a situação atual do mundo, por meio da pandemia do Covid-19, nos levou à seguinte reflexão: "existe um modo de atender as crianças com deficiência, educacionalmente, de forma remota?" Para responder tal questionamento analisaremos como a rede pública de ensino de Jaboatão dos Guararapes contemplou o acompanhamento didático e metodológico das crianças com deficiência durante a pandemia do Covid-19, no segundo semestre do ano de 2020.

No dia 06 de fevereiro de 2020, o Excelentíssimo Senhor Presidente da República, Jair Bolsonaro, decretou na Lei No 13.979, as seguintes medidas como forma de tentar conter a propagação do vírus $\mathrm{SARS}-\mathrm{Cov}-2$, que dá origem ao 
Covid-19. Art. $3^{\circ}$ Para enfrentamento da emergência de saúde pública de importância internacional decorrente do coronavírus, poderão ser adotadas, entre outras, as seguintes medidas:

I - isolamento;

II - quarentena;

Partindo desse pressuposto e tendo em vista o aumento considerável de casos da doença, o Governo do Estado de Pernambuco elaborou o Decreto de $N^{\circ} 48810$ de 16/03/2020, Art. $6^{\circ}$-A, a partir do dia 18 de março de 2020, que decretou a suspensão do funcionamento das escolas, universidades e demais estabelecimentos de ensino, público ou privado, em todo o Estado de Pernambuco.

Seguindo ainda as medidas de proteção, o Município de Jaboatão dos Guararapes, por meio do Prefeito Anderson Ferreira, emitiu um Decreto Municipal, de $\mathrm{n}^{\circ} 24$, de 16 de março de 2020, visando à suspensão:

I - de aulas e atividades em bibliotecas no âmbito da SME, a partir do dia18 de março de 2020;

II - de aulas e do uso de equipamentos públicos das academias da saúde;

$\S \mathbf{1}^{\mathbf{0}}$. Na rede privada de ensino cujos estabelecimentos estão localizados no Município do Jaboatão dos Guararapes, ficando recomendada a suspensão de aulas na educação básica, fundamental, ensino médio e superior, a partir do dia 18 de março de 2020.

Com isso, nos trouxe um quadro que nos tem sido desafiador e ao mesmotempo inovador, pois através de tal momento inoportuno e inesperado surge a necessidade de adequar a Educação Especial e Inclusiva para essa nova realidade, na qual não se podia fazer presentes num mesmo espaço físico professores e estudantes.

\section{A EDUCAÇÃO ESPECIAL NO BRASIL}

Como discutido anteriormente, percebemos o quanto a Educação Especial teve uma trajetória lenta no Brasil em relação a outros países, pois, acreditava-se que pessoas com deficiência deveriam ser "excluídas" da sociedade de certa forma. Ao longo de muitas lutas, observa-se então o avanço de pensamentos inovadores e começa-se a pensar na Educação Especial de modo isolado. A princípio, através das Escolas Especiais que eram destinadas apenas a pessoas com deficiência. Contudo, por meio de estudos feitos por grandes teóricos, surge então a necessidade de incluir essas pessoas nas unidades regulares de ensino, onde se unificou a Educação Especial 
à Inclusiva. Vygotsky (1932, p. 3) cita que: "na ausência do outro, o homem não se constrói homem", o que em outras palavras significa que todos precisam da intervenção do próximo para interagir e agregarconhecimento. A educação inclusiva tomou força no Brasil por volta dos anos 90 e se consolidou em meados de 1994, através da Declaração de Salamanca, que "define políticas, princípios e práticas da Educação Especial e influi nas Políticas Públicas de Educação”. (UNESCO, 1994, p. 3).

Segundo a Declaração de Salamanca, todas as crianças têm o direito à educação:

O princípio fundamental desta linha de ação é de que as escolas devem acolher todas as crianças independentemente de suas condições físicas, intelectuais, sociais, emocionais, linguísticas ou outras. Devem acolher crianças com deficiência e crianças bem dotadas, crianças que vivem nas ruas e que trabalham crianças de minorias lingüística, étnicas ou culturais e crianças e crianças de outros grupos ou zonas desfavoráveis ou marginalizadas. (DECLARAÇÃO DE SALAMANCA, 1994, p. 17-18).

A partir de então, tivemos um crescente avanço na Educação Especial. A Lei de Diretrizes e Base da Educação (LDB) 9.394/96, no parágrafo 58, diz que:

Entende-se por Educação Especial, para os efeitos desta Lei, a modalidade de educação escolar oferecida preferencialmente na rede regular de ensino, para educandos com deficiência, transtornos globais do desenvolvimento e altas habilidades ou superdotação. (LDB 9.394/96, Art. 58.).

Garantimos, assim, o acesso e obrigatoriedade do Estado em assistir essas crianças. Contudo, em relação à Educação Especial, ainda havia muito a ser trabalhado, como por exemplo, a verdadeira inclusão das crianças com deficiência, e foi nesse contexto que se uniu então a Educação Inclusiva, através de lutas para a inclusão de tais alunos na escola regular. Surge então a Lei Ordinária Federal n ○12.764 /2012, ou Lei Berenice Piana, nome concedido em homenagem a coautora da lei, mãe de uma criança autista e militante da causa. Essa grande ação vem nos lembrar do que falava o Pedagogo Paulo Freire (1980, p. 93): “A inclusão acontece quando se aprende com as diferenças e não com as igualdades." Para que essa inclusão aconteça, de fato, devemos viver esse pensamento em nossas atitudes ativamente.

\section{EDUCAÇÃO INCLUSIVA NO BRASIL}

Podemos dizer que o intuito de inicialização da inclusão no Brasil se deu por volta dos anos de 1857, ainda no reinado de D. Pedro I, através da fundação do “Imperial Instituto dos Surdos-mudos". Após 100 anos, veio a mudar seu nome para "Instituto Nacional de Educação de Surdos" (INES), centro de referência nacional na 
área da surdez, que foi um pontapé inicial, por assim dizer, na inclusão das pessoas com deficiência no país. É importante salientar que as escolas e classes especiais passaram a ter um elevado número de alunos com deficiência e que não necessitariam estar ali. Assim, verificou-se que a organização da Educação Especial e de classes especiais se deu em consequência da Lei 5.692/71, com a criação do Centro Nacional de Educação Especial (CENESP) e, posteriormente, a estruturação da Secretaria de Estado de Educação e do Serviço de Educação de Excepcionais, que passa a denominar-se Departamento de Ensino Especial.

Para Vygotsky (1989), a criança com deficiência tem a mesma capacidade de aprendizado e desenvolvimento que qualquer outra criançadenominada erroneamente de normal, bastando que a mesma tenha os estímulos necessários para que isso aconteça. Segundo o autor:

a essência psicológica da formação das reações condicionadas no cego (a leitura pelo sentido do tato) e no surdo (a compreensão da linguagem pelo movimento dos lábios) é absolutamente igual a da 'criança normal' e, portanto também, a natureza do processo educativo das crianças com deficiência, no essencial, é igual que na educação das 'crianças normais'. (VYGOTSKY, 1989, p. 3).

A Educação Inclusiva surgiu no Brasil com o intuito de agregar "forças" à Educação Especial, tendo em vista o contexto da Educação Especial no Brasil, que até então, se tratava de uma Educação "excludente", onde a criança com deficiência tinha o direito à Educação, porém, não tinha seu lugar na sala de aula regular, mas apenas em escolas especiais, que eram separadas por "modalidades específicas", como por exemplo, crianças autistas apenas estudariam com crianças autistas, crianças surdas apenas com crianças surdas, e assim sucessivamente. Não se pensava numa inclusão como um todo.

Conforme citação de Mazzotta (2001, p. 15):

A defesa da cidadania e do direito à educação das pessoas portadoras de deficiência é atitude muito recente em nossa sociedade. Manifestando-se através de medidas isoladas, de indivíduos ou grupos, a conquista e o reconhecimento de alguns direitos dos portadores de deficiências podem ser identificados como elementos integrantes de políticas sociais, a partir de meados deste século. (MAZZOTTA, 2001, p. 15).

Entendemos que a Educação Especial e a Educação Inclusiva andam de mãos dadas a pouco tempo. Sabemos que a perspectiva da Educação Inclusiva é que todas as pessoas tenham o direito a Educação e, para garantir o direito de todos, surge a 
obrigatoriedade da inserção desses alunos nas escolas, através da Lei de Diretrizes e Bases da Educação Brasileira(LDB) 9.634/96. Um pouco mais à frente surge a Lei Brasileira de Inclusão (LBI) $n^{\circ} 13.146 / 2015$ ou Estatuto da Pessoa com Deficiência (EPD), que institui a inclusão social e a cidadania da pessoa com deficiência, com o intuito de assegurar e promover, em condições de igualdade, o exercício dos direitos e das liberdades fundamentais.

Desse modo, podemos dizer que a modalidade da Educação Especiale Inclusiva é algo relativamente recente, e deve ser aprimorado de modo que todas as pessoas com deficiência sejam, de fato, inseridas nas unidades de ensino, assim como relata a especialista Fabiana Barrocas na Revista Construir (2020, p. 42):

Ao contrário do que se acredita, a experiência de vivenciar essa inclusão pode engrandecer tanto o aluno, quanto quem o inclui, como por exemplo, nos casos da vivência escolar, nos quais o professor pode reavaliar valores e princípios com seus alunos, ensinando e aprendendo a conviver com as diferenças. (BARROCAS, 2020, p. 42).

Somos levados a refletir, então, que a inclusão está muito além do contexto escolar, contudo, como profissionais da educação, devemos dar uma ênfase nesse tópico, pois é extremamente importante que todas as pessoas estejam inseridas na sociedade, independente de suas dificuldades, e esta inclusão pode ser facilitada por meio das diversas ferramentas tecnológicas disponíveis nos dias atuais.

\section{Tecnologias educacionais utilizadas no período de pandemia no Brasil}

É tido como Tecnologia Educacional todo o tipo de recurso utilizado para a facilitação do aprendizado. Segundo Polegatch (2013),

Entende-se por tecnologia o resultado da fusão entre ciência e técnica. O conceito de tecnologia educacional pode ser enunciado como o conjunto de procedimentos (técnicas) que visam "facilitar" os processos de ensino e aprendizagem usando a ciência. (POLEGATCH, 2013, p. 07).

Com isso, entendemos que as tecnologias podem ser desde um simples pedaço de papel e um lápis, até as tecnologias atuais e modernas, como por exemplo, a internet, os tablets, smartphones, dentre outros, e todos esses recursos podem e devem ser utilizados de maneira a inteirar as metodologias tradicionais de ensino, levando ao melhor desenvolvimento e crescimento cognitivo, interativo, motor e sensório da criança com deficiência. Contudo, vale salientar que nenhum recurso tem o poder de desenvolver por si só essas áreas, mas sim, dependem de um “intérprete”, uma pessoa 
para guiar a utilização de tais recursos, levando assim a um melhor aproveitamento das tecnologias.

No ano de 2020, especificamente no mês de março, as escolas municipais e particulares se viram obrigadas a reinventarem seus métodos educacionais devido a uma pandemia global da qual se fez necessário um distanciamento social e, consequentemente, a paralisação das aulas presenciais nas escolas e universidades. Com isso, houve então a necessidade de realizar as aulas de forma remota, levando ao uso constante de ferramentas virtuais, assim como as plataformas digitais (Google Classrom, Zoom, Hangouts, Google Meet, dentre outros). Para Rubem Alves (2016), escritor, pedagogo e filosofo brasileiro, "o professor não deve ensinar, pois os conteúdos já se encontram na internet, mas sim ensinar a pensar." A questão é: como fazer isso de forma remota?

Sabemos que o ser humano é moldado e inspirado por seu meio e não é diferente quando falamos de tecnologias, portanto, cabe a nós nos reinventarmos e nos adaptarmos a essa nova realidade. Segundo Castells (1999, p. 55), trata-se de uma revolução digital em que "a informação representa o principal ingrediente de nossa organização social, e os fluxos de mensagens e imagens entre as redes constituem o encadeamento básico de nossa estrutura social." (CASTELLS, 1999, p. 55).

A tecnologia está ao nosso redor e devemos tê-la como aliada em momentos oportunos. O processo de integração das tecnologias digitais na ação pedagógica deveria corresponder à existência de modelos pedagógicos e de currículos que dessem significado educativo ao uso das tecnologias educacionais em sala de aula e para além dela, contudo, muitos professores se encontraram desatualizados com relação às novas tecnologias e precisaram do apoio de outros profissionais.

Com a pandemia, houve o aumento considerável das ferramentas tecnológicas, contudo, nem todos os alunos têm acesso a essas tecnologias, como exemplo disso, temos os alunos das redes municipais, enfaticamente, na rede municipal de Jaboatão dos Guararapes, onde não houve aulas virtuais. Em virtude dessa condição, buscamos entender como foram contempladas as crianças deste município, especificamente as que possuem algum tipo de deficiência, visto que para elas a interação é parte fundamental de seu desenvolvimento cognitivo. 


\section{A PANDEMIA DO COVID - 19 E AS ESTRATÉGIAS DO ENSINO REMOTO}

Em meados do mês de dezembro do ano de dois mil e dezenove, foi detectado um novo vírus na China, variante do Covid, instituído como Covid - 19, que deu origem a uma nova infecção viral, o coronavírus. Ele tem a capacidade de deteriorar, em velocidade absurda, o sistema respiratório humano, comprometendo em grande maioria as pessoas com imunidade baixa ou comprometida. No início de fevereiro de 2020, mais precisamente no dia 06 de fevereiro, foi decretada a Lei de $\mathrm{n}^{\circ} \mathrm{N}^{\circ} 13.979$ para o enfrentamento do vírus no Brasil, estipulando o distanciamento social como forma de conter a expansão em massa da variante. Em 18 de março de 2020 o Governo do estado de Pernambuco decreta a Lei $N^{\circ} 48.830$ a qual proíbe as aulas presenciais no Estado, seguida do Decreto Municipal de $N^{\circ} 24$ do ano de 2020, complementando o que já havia no decreto Estadual, paralisando assim as aulas em escolas particulares ou públicas, assim como as faculdades e universidades. Houve o intuito de prevenir a saúde das crianças e professores, o que resultou em um momento inédito na educação brasileira: as aulas remotas.

Tal situação não foi previamente analisada, tendo em vista o caráter de urgência, nos levando a lacunas não preenchidas no que diz respeito à Educação Especial e Inclusiva, pois, entendemos que se faz obrigatório a inserção de alunos com deficiência na educação, como previsto na Constituição de 1988, Art. 205, Art. 206 parágrafo I, e ainda $\mathrm{Na}$ Lei De Diretrizes de Base da Educação (LBD) Lei ${ }^{\circ}$ 9.394/96.

Ainda no pensamento da educação inclusiva, podemos dizer que surge então outro grande desafio: o de consolidar o que foi garantido por lei e realizar essa integração e inclusão dentro do âmbito escolar, tendo em vista a necessidade de inserção social desse grupo que antes fora excluído da sociedade como um todo.

Contudo, devemos levar em consideração as inúmeras e inusitadas situações que podem levar ao distanciamento social do indivíduo e buscar inovações curriculares e estratégicas que façam com que esse mesmo indivíduo desenvolva cognitivamente, mesmo distante da sala de aula, buscando envolver além dos meios digitais a interação da família nesse contexto, fazendo com que não se perca tal interação, tão importante para esse desenvolvimento. Santos (2020), no seu recente trabalho "A cruel Pedagogia do Vírus" cita que a pandemia nos permite ver o modo como foi interpretado e avaliado, determinando o futuro da civilização em que vivemos. Estas aparições, ao contrário de outras, são reais e vieram para ficar. A 
pandemia é uma alegoria. (SANTOS, 2020, p. 10).

Partindo desse pressuposto, vemos que a situação atual, mesmo que inusitada e inesperada, é algo que veio para uma mudança real e permanente na área da Educação e, por mais que pareçamos despreparados, devemos nos atualizar e aprimorar todos os meios e ainda mais com relação à Educação Especial e Inclusiva, por se tratarem de crianças que na maior parte das vezes "dependem" de algum interventor, seja um professor de apoio, seja o (a) professor (a) titular, seja algum membro familiar. Eles precisam desse ponto seguro para um melhor desenvolvimento e, por essa razão, necessitam de uma atenção maior, porém, o que percebemos é que ainda estamos em defasagem quanto a esse apoio e necessitamos usar esse tempo para o amadurecimento estrutural de tais aulas, identificando a melhor forma de desenvolver um método eficaz para essa modalidade.

\section{METODOLOGIA}

Quanto aos procedimentos, este artigo utilizou-se de uma pesquisa bibliográfica, além de uma pesquisa de coleta de dados, pois se utilizou de um questionário elaborado por meio do Google Forms, destinado a 13 profissionais da área da Educação Especial e Inclusiva, no intuitode entender como se deram as aulas para crianças com deficiência na rede de ensino pública de Jaboatão dos Guararapes.

Quanto à abordagem, a pesquisa é qualitativa, pois tem o intuito de compreender como as aulas destinadas às crianças com deficiência dentro da rede municipal de ensino de Jaboatão dos Guararapes foram ministradas no período pandêmico.

Quanto aos objetivos, a pesquisa apresentada é descritiva, pois se trata de um relato documental. A pesquisa é também exploratória, pois busca enfatizar a experiência das aulas remotas no contexto da Educação Especial e Inclusiva.

Assim sendo, a partir das análises relacionadas às estratégias didáticas e metodológicas adotadas pela rede municipal de ensino no município de Jaboatão dos Guararapes, será possível compreender como as crianças com deficiência foram atendidas durante a pandemia do Covid-19.

\section{RESULTADOS}

Diante dos resultados obtidos durante a coleta de dados que tiveram base na pesquisa elaborada e direcionada aos profissionais que atuam e/ou atuaram na 
Educação Especial e Inclusiva, durante o período da pandemia do Covid - 19 em Jaboatão dos Guararapes, pudemos chegar a conclusão de que as estratégias e metodologias utilizadas no ensino especial e inclusivo foram quase que inexistentes durante o período analisado.

Há quanto tempo trabalha na Educação Especial e Inclusiva?

9 respostas

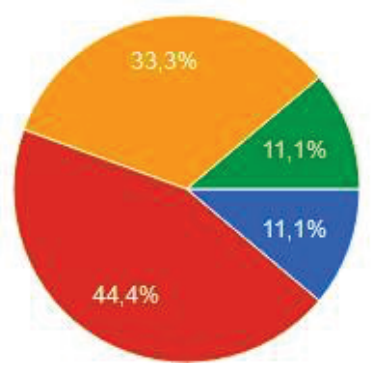

Mais ou menos 1 ano

De 2 á 5 anos

Sempre trabalhei na área

Há 15 anos

Fonte: As autoras

Tal experiência nos leva à compreensão de que esses profissionais conseguem avaliar aquilo que pode ser relevante ou não no contexto a qual foi analisado durante essa pesquisa, o que nos levou ao argumento demonstrado quando perguntado aos entrevistados: "Acredita que mesmo durante a pandemia existiu a inclusão dos alunos especiais nas salas on-line?" Observamos que a maioria respondeu que não acreditava ter existido tal inclusão durante esse período, como visualizado no gráfico abaixo:

Acredita que mesmo durante a pandemia existiu a inclusão dos alunos especiais nas salas on-line?

9 respostas

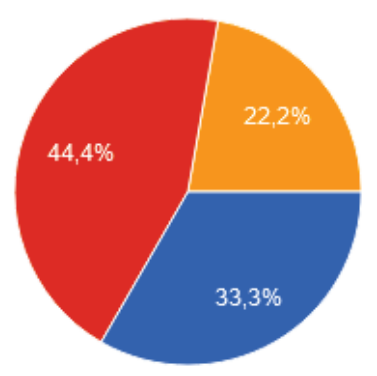


Com isso, entendemos que de fato nem todos os direitos das crianças que se enquadram na Educação Especial e Inclusiva foram contemplados. Contudo, as justificativas dadas por estes profissionais quando indagados, foram: "Uma das principais questões sobre inclusão em escolas regulares é a interação com outros estudantes". Qual a importância disso durante a pandemia? Quais ações podem ser boas práticas para garantir que os alunos com deficiência sigam tendo esses momentos com os colegas? "O profissional "X" respondeu: "Nesse momento desafiador as interações físicas entre crianças não é possível dado às questões de saúde pública”. Criar estratégias é fundamental para que isso ocorra de modo seguro. "O professor precisa desenvolver práticas pedagógicas inclusivas, possíveis para a sua práxis, viabilizando a inclusão desde já”. Penso que não há receitas, mas há ações possíveis de serem replicadas e adaptadas ao contexto".

Entendemos nessa fala que apesar de não terem a assistência necessária, as crianças da Educação Especial e Inclusiva tiveram de algum modo o pensamento voltado para suas necessidades, visando atender não somente a área educacional, como também, priorizando a saúde física de tais estudantes. Ainda no segmento das aulas durante o período pandêmico realizamos a seguinte pergunta:

\section{Com relação às aulas remotas, você acredita que houve um bom aproveitamento dos alunos com deficiência? \\ 9 respostas}
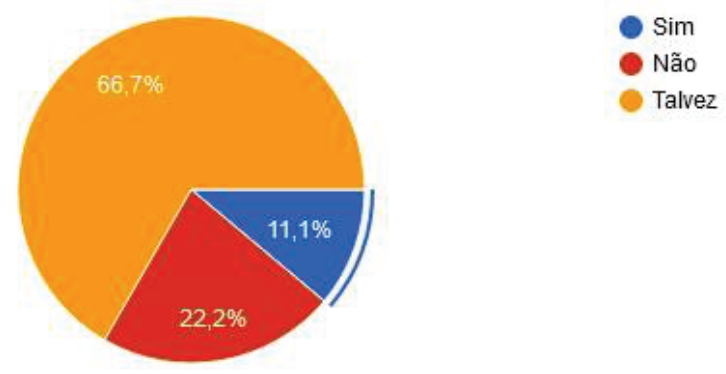

\section{Fonte: As autoras}

Embora tal mudança tenha sido planejada, ou tenha existido adaptações nas atividades propostas durante as aulas remotas da Educação Especial e Inclusiva, concluímos que os professores, auxiliares de apoio aos alunos com deficiência, psicopedagogos, não estavam totalmente preparados para essa nova realidade, sendo necessária uma reciclagem metodológica para se adaptarem ao "novo normal”. 
Sobre essa necessidade foi elaborada a seguinte pergunta: "Em sua opinião, acredita que os professores deveriam ter uma formação especializada para lidarcom as aulas remotas, virtuais, etc.? "As respostas foram representadas no gráfico abaixo:

Na sua opinião, acredita que os professores deveriam ter uma formação especializada para lidar com as aulas remotas, virtuais, etc.

9 respostas

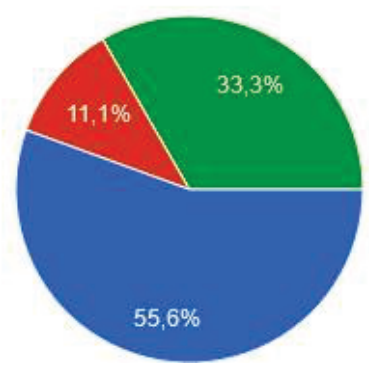

Acredito que sim

Sim , principalmente para Educação Especial e Inclusiva

Acredito que não seja necessário, pois estamos aprendendo aos poucos

Sim, para todos os âmbitos

educacionais

Fonte: As autoras

Percebemos por meio das respostas dos entrevistados que 55,6\% deles acreditam que deveria existir uma formação especializada direcionada para os profissionais que lidam com a educação, principalmente a Especial e Inclusiva, para que consigam adaptar às atividades e metodologias de ensino de modo a contemplar tal modalidade educacional.

Contudo, esse envolvimento e desenvoltura não dependem apenas da rede de ensino, mas também de todos os envolvidos. Diante de tal questionamento abordamos os entrevistados com a seguinte indagação: "Em sua opinião, a ação do professor (a) durante o período de pandemia, necessita mais do apoio dos pais ou responsáveis pela criança? De que modo?" Obtivemos do profissional "Y" a seguinte resposta: "Sim, a participação da família é fundamental no desenvolvimento do aluno. Ela sabe quais atividades ela tem competência pra desenvolver e o auxiliar." Do profissional " $X$ " foi dada a seguinte resposta ao mesmo questionamento: "A participação das famílias é sempre bem vinda, pois está sendo o nosso suporte nesse momento."

Ainda no contexto de apoio escolar para a Educação Especial e Inclusiva durante a pandemia argumentamos o seguinte:

Você obteve ajuda de mais algum profissional ao desenvolver as atividades para os alunos especiais? De que modo?

O profissional "z" respondeu: "na nossa formação continuada já temos 
orientações nas adaptações". E o profissional "W" respondeu: "sempre trabalhamos com adaptações de materiais para melhorar o atendimento". E ainda o profissional "y" respondeu: "sim, o psicólogo". Levando a compreensão de que todo trabalho desenvolvido é destinado às crianças com deficiência deve ser realizado em conjunto, buscando assim um melhor aproveitamento, ainda mais durante períodos de distanciamento como o vivido atualmente. Compreendemos que a família ou responsável pela criança tem fundamental importância em seu desempenho escolar, seja ela por meio presencial ou virtual, porém temos nesse ponto mais uma grande dificuldade: a desigualdade social. Acreditamos ser um dos fatores influenciadores da falta de aprofundamento e desenvolvimento de atividades que englobassem todos os alunos, de forma inclusiva como deveria ser, já que grande parte, se não toda a sociedade escolar da rede municipal, vem de uma situação social onde não existe sequer acesso à internet, o que consideramos, no momento, um instrumento principal de comunicação entre escola e estudante e sem esse recurso as aulas remotasde fato não têm como existir, ou seja, mais uma vez, de certo modo, as crianças com deficiência têm seu direito negado por não haver uma estratégia, seja ela causada pela negligência de uma das partes. Sobre esse argumento realizamos a seguinte pergunta:

E quanto às escolas municipais, acredita que tenham tido êxito no desenvolvimento das aulas remotas direcionadas ás crianças deficientes?

9 respostas

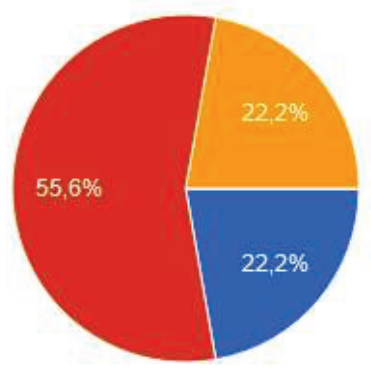

Não houve qualquer desenvolvimento Sim, porém não totalmente

- Acredito que foram atendidas conforme a necessidade de cada especificidade

Sim, houve de fato uma atenção para educação especial e Inclusiva durante a pandemia

\section{Fonte: As autoras}

Nesse caso, é visto que existe sim um despreparo a ser reparado, a fim de fazer valer os direitos garantidos por lei. A Lei de Diretrizes e Bases da Educação Nacional (LDB), no 9.394/96, no Capítulo III, art. $4^{\circ}$, inciso III, diz que é dever do Estado garantir o "atendimento educacional especializado gratuito aos educandos com necessidades especiais, preferencialmente na rede regular de ensino". E para que isso seja garantido, de fato, deve-se haver uma mudança integral na rede de ensino, para 
que o acesso seja permitido a todos os estudantes de forma a garantir a equidade.

Por fim, segue abaixo um quadro sobre os pontos positivos e negativos encontrados por meio desta pesquisa durante o período pandêmico.

\begin{tabular}{|c|c|}
\hline $\begin{array}{l}\text { Pontos positivos } \\
\text { observados durante o } \\
\text { periodo de pandemia na } \\
\text { Educaça Especial e } \\
\text { Inclusiva. }\end{array}$ & $\begin{array}{l}\text { Pontos negativos } \\
\text { observados durante o } \\
\text { periodo de pandemia na } \\
\text { Educaça Especial e } \\
\text { Inclusiva. }\end{array}$ \\
\hline A prioridade a vida. & $\begin{array}{l}\text { A Falta de planejamento e } \\
\text { metodologias que } \\
\text { atendessem as } \\
\text { necessidades das crianças } \\
\text { da Educação Especial e } \\
\text { Inclusiva. }\end{array}$ \\
\hline
\end{tabular}

Fonte: as autoras

Entendemos que o maior ponto positivo, sem dúvidas, foi a prioridade da vida, em todos os âmbitos, porém, os pontos negativos observados, ainda através da pesquisa, foi a falta de um planejamento eficaz à Educação Especial e Inclusiva, assim como a utilização das metodologias que atendessem às necessidades do público proposto.

\section{CONSIDERAÇÕES FINAIS}

Considerando os resultados de pesquisa, podemos concluir que diante das dificuldades enfrentadas durante o período da Pandemia do Covid-19 no município de Jaboatão dos Guararapes existiram divergências entre os planejamentos e execuções de métodos de ensino que fossem realmente eficazes diante de tal contexto. Por meio das respostas obtidas pelo questionário, percebemos ainda que não houve sequer um apoio maior da parte da Secretaria de Educação da rede municipal de Jaboatão dos Guararapes com relação às aulas durante o período de pandemia, levando o(a) professor(a) a ausência de recursos apropriados para a elaboração e execução de atividades ou aulas remotas que preenchessem esse espaço tão necessário.

Percebeu-se ainda que diversos fatores que contribuíram para que essa inclusão não fosse garantida, mesmo que por lei ela exista. Como exemplo disso tem a falta de recursos dos alunos em relação aos meios acessíveis de uma possível aula on-line. Devemos nos atentar às necessidades desses alunos e tentar da melhor forma fazer valer seus direitos como o de qualquer estudante. Ainda que em meio a uma pandemia, essa inclusão precisa ser validada e cumprida.

Não podemos deixar de enfatizar que a prioridade sempre será a vidae, nesse momento de pandemia, é nisso que devemos focar. Ainda assim, tudo o que foi enfrentado durante o período da pandemia no novo coronavírus, serviu para nos 
atentarmos às mudanças que necessitamser realizadas no âmbito educacional. Mudanças essas que devem ser pensadas para utilização tanto em momentos como o que estamos enfrentando, quanto momentos futuros, onde estudantes necessitem ter acesso às aulas de forma virtual em decorrência das suas comorbidades e ainda assim ter seu direito a educação assegurado de forma efetiva e não apenas na lei. Que possamos, diante desse enfrentamento, tirar lições para toda a vida.

\section{REFERÊNCIAS}

BELLONI, Maria Luiza; GOMES, Nilza Godoy. Infância, mídias e aprendizagem: autodidaxia e colaboração. Educ. Soc., Campinas, vol. 29, n. 104 - Especial p. 717746, outubro 2008. Disponível em: http://www.cedes.unicamp.br. Acesso em: 20 abr, 2021.

BRASIL. Estatuto da Criança e do Adolescente (ECA). Lei 8.069 de 13 de julho de 1990.

BRASIL. Leis de Diretrizes e Bases da Educação Brasileira (LDB). Lei 9.394 de 20 de dezembro de 1996.

CASTELLS, Manuel. A sociedade em rede. São Paulo: Paz e Terra, 1999.

DECLARAÇÃO DE SALAMANCA. Princípios, Políticas e Práticas na Área das Necessidades Educativas Especiais. A/RES/48/96, Resolução das Nações Unidas adotada em Assembléia Geral.

FARAH, Fabiana Barrocas Alves; Notícias Construir. Ed. Construir. Recife, Março de 2020.

FREIRE, Paulo. Pedagogia do oprimido. 8. ed. Rio de Janeiro: Paz e Terra, 1980.

MAZZOTTA, Marcos J. S. Educação Especial no Brasil - História e políticas públicas. 3. ed. São Paulo: Cortez, 2001.

MERCÚRIO, Regina. Disponível em: https://educacaointegral.org.br/reportagens. Acesso em : 20 abr. 2021.

MOREIRA, Marco Antônio. Teorias de Aprendizagens. EPU, São Paulo, 1995. Disponível em: https://www.infoescola.com/pedagogia/teoria-de-aprendizagemde-vygotsky/. Acesso em: 20 out. 2020.

POLEGATCH. Estudo sobre as Tecnologias Educacionais. Pós Graduação em Língua Espanhola. Universidade Tuiuti Do Paraná. Curitiba, 2013.

RUBEM ALVES. Disponível em: https://blogs.funiber.org/pt/formacaoprofessores/2016/09/20/funiber-rubem-alves-pensar. Acesso em: 02 abr. 2021. 
SANTOS, Boaventura de Sousa. A cruel pedagogia do vírus. Coimbra: Edições Almedina, 2020.

SHUARE, M. La psicologia soviética tal como yo la veo. Moscú: Editorial Progreso, 1990.

UNESCO. Disponível em: https://brasil.un.org/. Acesso em: 05 abr. 2021.

VYGOTSKY, L. S. Fundamentos de defectologia. La Habana: Pueblo y Educación, 1989. 


\section{APENDICE A - Questionário aplicado na pesquisa de campo}

\section{Pesquisa Acadêmica}

Pesquisa para trabalho de conclusão de curso

Uma das principais questões sobre inclusão em escolas regulares é a interação com outros estudantes. Qual a importância disso durante a pandemia? Quais ações podem ser boas práticas para garantir que os alunos com deficiência sigam tendo esses momentos com os colegas?

Texto de resposta longa

teve um bom recebimento devolutivo de familiares ou responsáveis por alunos com deficiência * sobre as atividades enviadas para casa?

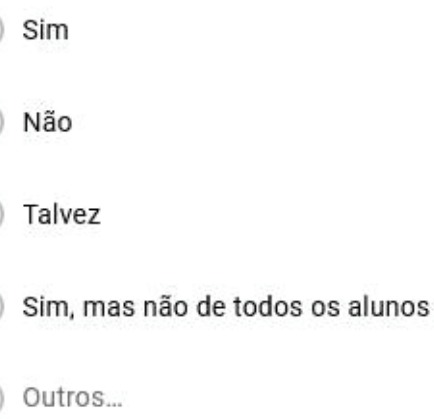

:::

Na sua opinião, a ação do professor (a) durante o periodo de pandemia, necessita mais do apoio dos pais ou responsáveis pela criança? De que modo?

Texto de resposta longa

presencial considerando o tempo distante da escola e dos colegas?

Texto de resposta longa

Quais lições você tirou de todo o período em que as aulas foram suspensas por conta do distanciamento social? 
Há quanto tempo trabalha na Educação Especial e Inclusiva? *
Mais ou menos 1 ano
De 2 á 5 anos
Sempre trabalhei na área
Outros...

Qual o maior desafio você enfrentou com a pandemia no âmbito educacional? *

Texto de resposta longa

Com relação às aulas remotas, você acredita que houve um bom aproveitamento dos alunos com deficiência?

Sim

Não

Talvez

Outros...

De que forma você acha que as aulas remotas funcionariam melhor no que diz respeito a Educação Especial e Inclusiva?

Texto de resposta longa

Você obteve ajuda de mais algum profissional ao desenvolver as atividades para os alunos especiais? De que modo?

Texto de resposta longa 